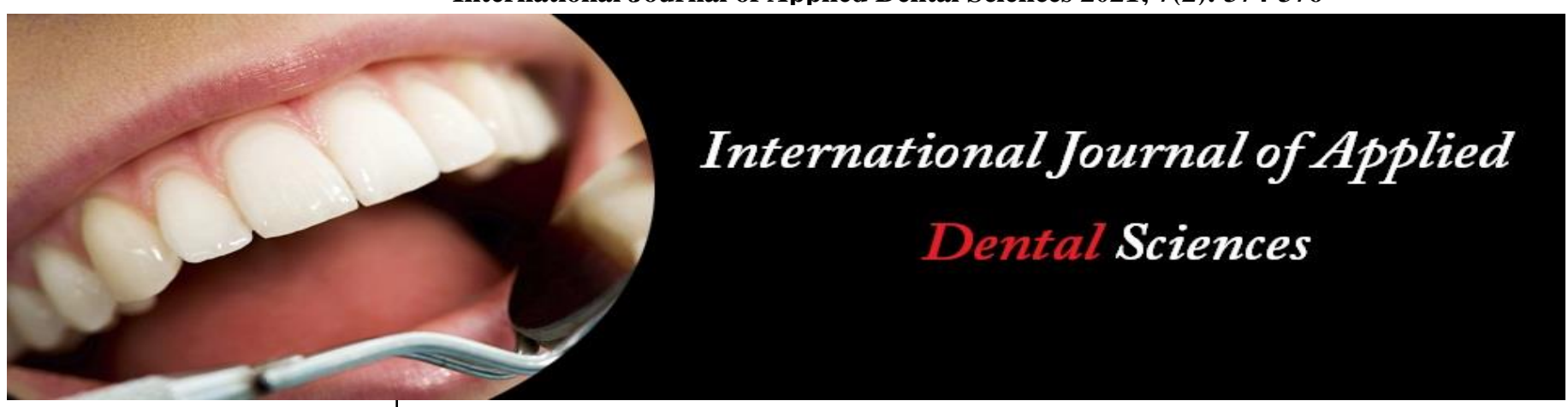

ISSN Print: 2394-7489

ISSN Online: 2394-7497

IJADS 2021; 7(2): 374-376

(C) 2021 IJADS

www.oraljournal.com

Received: 13-02-2021

Accepted: 15-03-2021

Dr. Pratiksha A Srivastava

Post Graduate Student,

Department of Prosthodontics

and Crown and Bridge,

Subharti Dental College, Swami

Vivekanand Subharti

University, NH-58, Meerut,

Uttar Pradesh, India

Dr. Chandan K Kusum

Reader, Department of

Prosthodontics and Crown and

Bridge, Subharti Dental College,

Swami Vivekanand Subharti

University, NH-58, Meerut,

Uttar Pradesh, India

Dr. Sumit Aggarwal

Professor, Department of

Prosthodontics and Crown and

Bridge, Subharti Dental College,

Swami Vivekanand Subharti

University, NH-58, Meerut,

Uttar Pradesh, India

Dr. Sumit Makkar

Private Practitioner

Department of Prosthodontics

and Crown and Bridge, Subharti

Dental College, Swami

Vivekanand Subharti

University, NH-58, Meerut,

Uttar Pradesh, India

\section{Immediate esthetic restoration of failed teeth in esthetic zone using socket shield technique: A case report}

\author{
Dr. Pratiksha A Srivastava, Dr. Chandan K Kusum, Dr. Sumit Aggarwal \\ and Dr. Sumit Makkar
}

DOI: https://doi.org/10.22271/oral.2021.v7.i2f.1234

\section{Abstract}

The long term success in implant dentistry has evolved from the success of osseo-integration to the best esthetic optimization in a case. The socket-shield technique provides a promising treatment adjunct to preserve the post-extraction tissues and provide esthetic success where the final prosthesis is comparable in look and emergence profile to the natural tooth/teeth.

Keywords: socket shield technique, immediate implant, esthetic zone, essix appliance

\section{Introduction}

Oral implantology has evolved into an accepted, predictable treatment for restoring lost teeth [1]. Dental implants have become a milestone in dentistry due to which numerous alternative oral therapies that could not be possible with conventional techniques have become possible. Today, the focus on treatment goals has also shifted from merely implant survival to treatment success. The main expectation of patients regarding implants besides a low cost-benefit ratio and time efficiency is the aesthetic outcome, especially regarding the long-term view ${ }^{[2]}$. In modern times where esthetics has become the prime factor, attention and emphasis is being given in preserving the buccal bone while an implant is placed following the removal of a tooth.

Removal of the tooth severs the rich PDL vasculature that supplies the alveolus bundle bone ${ }^{[3]}$. Preservation of roots of teeth have proved to be positive factor in retarding the resorption process. Therefore an innovative technique of placing implants in close contact with planned retained roots was developed thus protecting the buccal bone from resorption. The technique is known as the Socket Shield Technique (SST).

This clinical report describes immediate implant placement with the use of socket shield technique to provide a prosthesis with functionally and esthetically satisfactory outcome.

\section{Case report}

A 21-year old female patient reported to the Department of Prosthodontics, Subharti Dental College, Meerut, India with fractured maxillary central and lateral incisors and wished for its replacement.

Clinical evaluation revealed intact tooth structure and healthy soft tissue. Socket-shield procedure was planned and the treatment procedure was explained to the patient and a signed informed consent was taken. There was no associated relevant medical history.

\section{Procedure}

The surgical phase involved inducing local anesthesia at the treatment site (Fig.1). The root was sectioned in a mesiodistal direction along its long axis as far apical as possible using a long shank root resection bur coupled to high-speed handpiece. Sectioning divided the tooth root into facial and palatal halves with the intention of preserving the facial root section unmanipulated and attached to the tooth socket. Periotomes were inserted between the palatal root section and the alveolar socket wall to sever the PDL and this section of root was
Corresponding Author:

Post Graduate Student,

Department of Prosthodontics and Crown and Bridge,

Subharti Dental College, Swami

Vivekanand Subharti

University, NH-58, Meerut,

Uttar Pradesh, India 
carefully delivered without disturbing the facial root section. The remaining root section was reduced coronally $1 \mathrm{~mm}$ above the alveolar crest, and was thinned slightly to a concave contour by careful application in an apico-coronal and mesiodistal direction with a long shanked round diamond bur. The tooth socket's palatal wall and apex were then curetted to remove any tissue or infective remnants and the root section was checked for immobility with a sharp probe. With the preparation steps complete, the tooth root hereafter was known as the socket-shield (SS) (Fig. 2). An osteotomy was then sequentially prepared in the socket palatal to the SS via a prosthodontically planned surgical guide (essix appliance)
(Fig. 3). The implant platform was kept $2 \mathrm{~mm}$ below the facial crest (Fig. 4). The jumping gap was grafted with a xenogenic bone particulate (Fig. 5). Provisional restoration was given on implant after confirming its primary stability by implant stability quotient (ISQ) device. The same essix appliance which was used as surgical guide was used as provisional restoration by adding composite in the missing teeth region (Fig. 6). Approximately 4 months post implant placement, second-stage surgery was performed and healing abutments were placed. After which cement-retained PFM crowns were placed on each implant following proper prosthodontic protocols (Fig. 7).
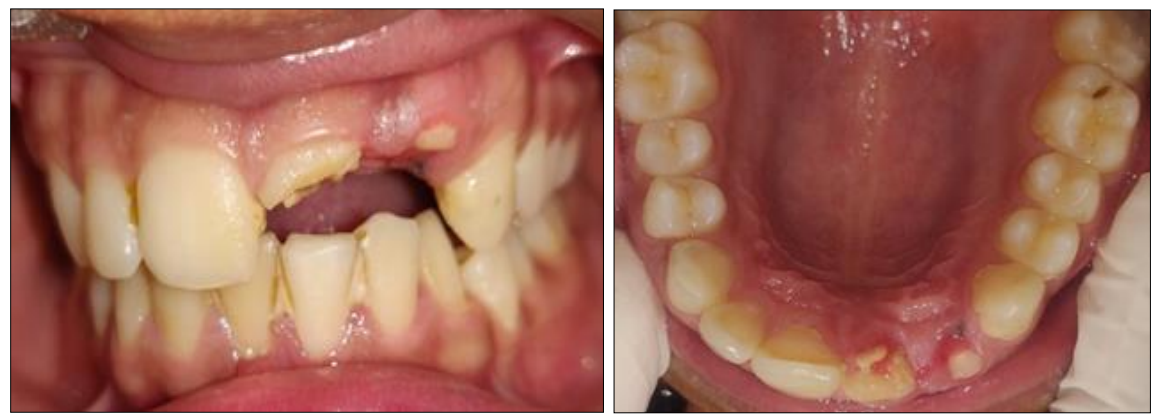

Fig 1: Pre-operative view

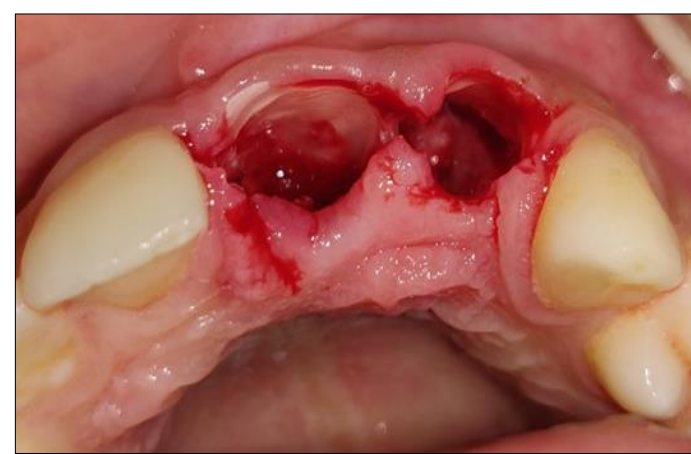

Fig 2: Shield preparation

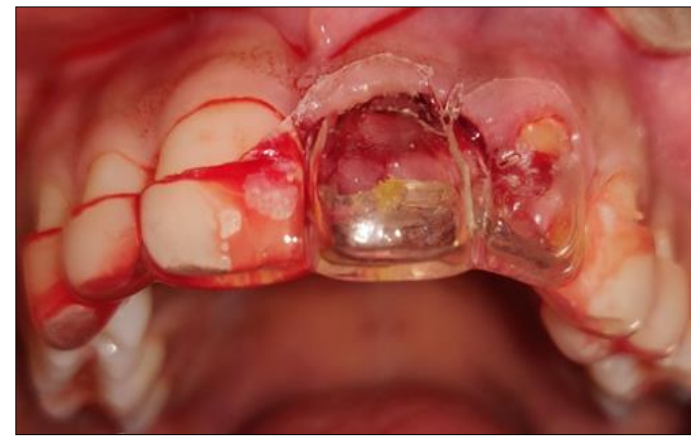

Fig 3: Essix appliance used as surgical guide

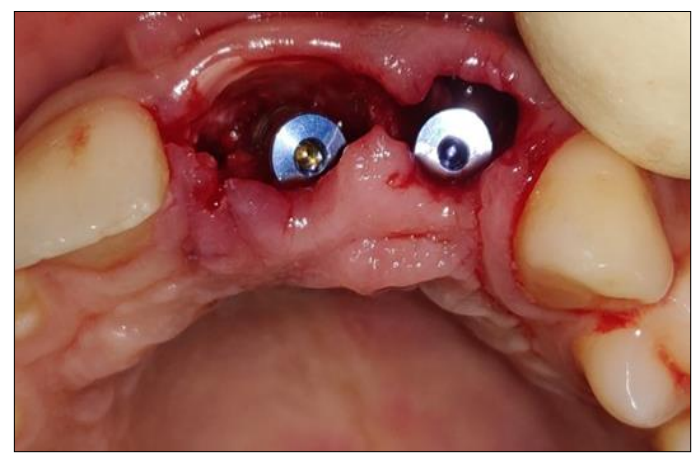

Fig 4: Implant placement

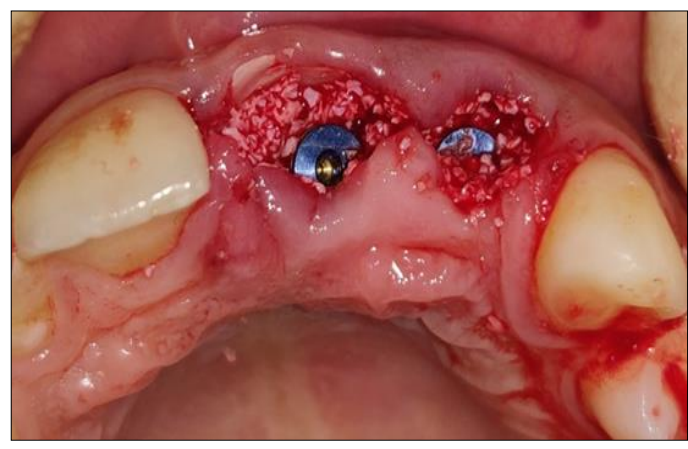

Fig 5: Jumping gap filled with biooss xenograft

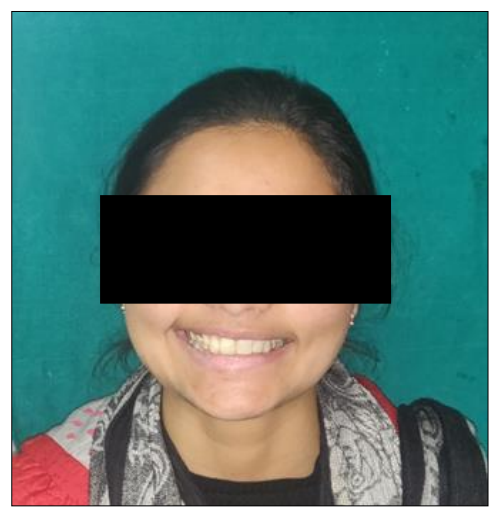

Fig 6: Interim prosthesis

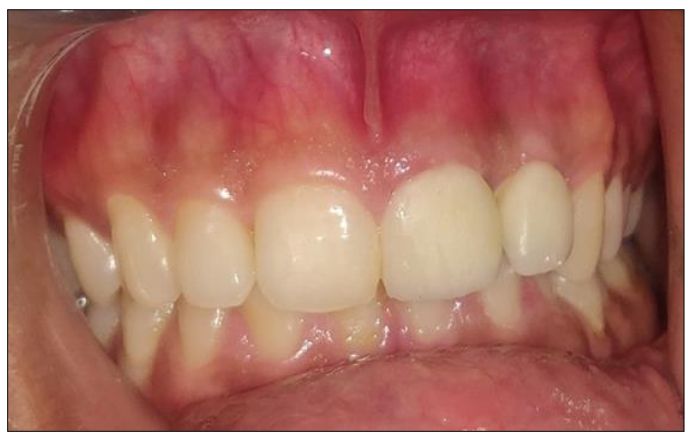

Fig 7: Final prosthesis 


\section{Discussion}

The principle is to prepare the root of a tooth indicated for extraction in such a manner that the buccal/ facial root section remains in-situ with its physiologic relation to the buccal plate intact. The tooth root section's periodontal attachment apparatus (periodontal ligament (PDL), attachment fibers, vascularization, root cementum, bundle bone, alveolar bone) is intended to remain vital and undamaged so as to prevent the expected post-extraction socket remodeling and to support the buccal/facial tissues ${ }^{[4]}$. The Socket Shield offers various advantage of immediate implant placement like comparable low morbidity, less esthetic risk ratio and favorable cost benefit ratio.

Abadzhiev et al. in his clinical study with 25 patients comparing the conventional approach for immediate implant placement using socket shield study. They concluded that the conventional approach was clearly inferior regarding the esthetic outcomes and tissue changes ${ }^{[5]}$.

The socket-shield is created by preparation of a tooth indicated for extraction at an immediate implant placement site, typically in the anterior maxilla. The socket-shield procedure starts by decoronating the tooth at $1 \mathrm{~mm}$ above the bone crest. However in this case decoronation was not required as only the root was left after tooth fracture, so the root is thereafter directly sectioned longitudinally into facial and palatal halves. Trying to be as minimally invasive as possible, gingival retractors were not used in this study as it might injure the periodontal ligaments and cause minute lacerations in the adjacent papilla. The palatal root section is delivered and any pathology present is cleared from the tooth apex. The facial root section is then concaved slightly with a long shank dental bur. The shield is prepared as in the original technique reported by Hurzeler et al. ${ }^{[6]}$ which avoids heat generation and possible shield dislodgment as well as the added cost that can result from drilling through the tooth since it requires new drills for each intervention.

The implant is then immediately placed palatal to the socket shield and the buccal gap preferably grafted with a slowresorbing bone substitute material, xenogenic bone particulate in this case. As they provide inert scaffold suitable for the new bone deposition from the surrounding bone or encourage growth of differentiated mesenchymal cells along the graft surface [7]. The use of xenogenic graft reduces the postoperative complication by avoiding harvesting of autogenous graft from a second surgical site. Moreover, the decades of use of the xenogenic bone graft supports its effectiveness and biocompatibility as a bone regenerative material ${ }^{[8]}$. As reported by Kumar PR and Kher $U$ the optimum space between shield and implant is $1.5 \mathrm{~mm}$ or more and a bone graft is suggested if the gap is more than $3 \mathrm{~mm}{ }^{[9]}$. As the gap was more than $3 \mathrm{~mm}$, grafting was done in the present case.

The temporary crown is fabricated chair side with an Sshaped emergence profile to allow for maximum infill of the coronal soft tissue around the interim and definitive restoration as reported by Gluckman et al. ${ }^{[10]}$. An essix appliance ${ }^{[11,12]}$ was used as a provisional restoration and also as a surgical guide in the present report. The fabrication of essix appliance was accomplished as followed by Santosa RE [13].

\section{Conclusion}

The use of socket shield technique (SST) with immediate implant in esthetic zone provides a promising treatment in preserving both the soft and hard tissue.

\section{References}

1. Sharma A, Kaushik M, Saleem M. Guided Bone Regeneration, IJDSIR 2020;3(4):537-542.

2. Baumer D, Zuhr O, Rebele S, Schneider D, Schupbach P, Hurzeler M. The socket-shield technique: first histological, clinical, and volumetrical observations after separation of the buccal tooth segment - a pilot study. Clin Implant Dent Relat Res 2015;17(1):71-82.

3. Gluckman H, Salama M, Du Toit J. Partial Extraction Therapies (PET). Part 2: Procedures and technical aspects. Int $\mathbf{J}$ Periodontics Trestorative Dent 2017;37:377-385.

4. Gluckman H, Salama M, Du Toit J. Partial Extraction Therapies (PET). Part 1: Maintaining alveolar ridge contour at pontic and immediate implant sites. Int $\mathbf{J}$ Periodontics Trestorative Dent 2016;36:681-687.

5. Hurzeler MB, Zuhr O, Schupbach P, Rebele SF, Emmanouilidis N, Fickl S. The socket-shield technique: a proof of principle report. J Clin Periodontol 2010:37;85562.

6. Gluckman H, Nagy K, Du Toit J. Prosthetic management of implants placed with the socket-shield technique. J Prosthet Dent 2019;121(4):581-585.

7. Du Toit J, Gluckman H. The modified socket-shield technique. J Craniofac Surg 2018;29(7), 2005;6(11).

8. Liu J, Kerns DG. Mechanisms of Guided Bone Regeneration: A Review. Open Dent J 2014;8(1):56-65.

9. Kumar PR, Kher U. Shield the socket: procedure, case report and classification. Journal of Indian Society of Periodontology 2018;22(3):266.

10. Gluckman H, Salama M, Du Toit J. A retrospective evaluation of 128 socket-shield cases in the esthetic zone and posterior sites: partial extraction therapy with up to 4 years follow-up. Clin Implant Dent Relat Res 2018;20(2):122-129.

11. Sheridan JJ, Ledoux W, McMinn R. Essix retainers: fabrication and supervision for permanent retention. J Clin Orthod 1993;27:37-45.

12. Moskowitz EM, Sheridan JJ, Celenza F, Tovilo K, Munoz AM. Essix appliances. Provisional anterior prosthesis for pre and post implant patients. N Y State Dent J 1997;63:32-35.

13. Santosa RE. Provisional restoration options in implant dentistry. Australian dental journal 2007;52(3):234-42. 